\title{
Estudo retrospectivo de doenças diagnosticadas em galinhas coloniais (Gallus gallus domesticus) na região sul do Rio Grande do Sul, em um período de 20 anos (2000 -
} 2020)

\author{
Retrospective study of diseases diagnosed in free range chickens (Gallus gallus domesticus) in the \\ southern region of Rio Grande do Sul, over a period of 20 years (2000 - 2020) \\ Estudio retrospectivo de enfermedades diagnosticadas en pollo colonial (Gallus gallus domesticus) \\ en la región sur de Rio Grande do Sul, durante un período de 20 años (2000 - 2020)
}

Recebido: 02/08/2021 | Revisado: 09/08/2021 | Aceito: 13/08/2021 | Publicado: 15/08/2021

Rosimeri Zamboni

ORCID: https://orcid.org/0000-0003-0709-660X Universidade Federal de Pelotas, Brasil

E-mail: rosi_zamboni@yahoo.com.br

Taina dos Santos Alberti

ORCID: https://orcid.org/0000-0001-7568-8143 Universidade Federal de Pelotas, Brasil

E-mail: taina_alberti@yahoo.com

Fabiano da Rosa Venancio

ORCID: https://orcid.org/0000-0002-4769-9360 Universidade Federal de Pelotas, Brasil

E-mail: fabianodarosavenancio@gmail.com

Ana Lucia Schild

ORCID: https://orcid.org/0000-0003-2470-4785 Universidade Federal de Pelotas, Brasi

E-mail: alschild@terra.com.br

Gilberto D'Ávila Vargas

ORCID: https://orcid.org/0000-0002-5126-3607 Universidade Federal de Pelotas, Brasil

E-mail: gdavilavargas@gmail.com

Eliza Simone Viégas Sallis

ORCID: https://orcid.org/0000-0003-3033-9876 Universidade Federal de Pelotas, Brasil

E-mail: esvsallis@yahoo.com.br

\begin{abstract}
Resumo
O objetivo desse estudo foi identificar e descrever as principais doenças que acometeram galinhas criadas em sistemas alternativos, encaminhadas ao Laboratório Regional de Diagnóstico da Faculdade de Veterinária da Universidade Federal de Pelotas (LRD/UFPel), entre os anos de 2000 e 2020. Foram revisados os protocolos de necropsia de galinhas domésticas encaminhadas ao LRD/UFPel, nos últimos 20 anos. Nesse período foram recebidas 565 amostras correspondentes a cadáveres e órgãos de galinhas domésticas, sendo 229 de criações alternativas. Dos 229 casos, 203 $(88,64 \%)$ tinham diagnóstico conclusivo. As principais doenças diagnosticadas foram bacterianas com 79/203 $(38,92 \%)$ casos, seguidas das parasitárias 59/203 (29,06\%). Dentre as doenças bacterianas, as salmoneloses foram as mais frequente com 26/79 casos, sendo isolados 22/26 biovares Gallinarum e 4/26 Pullorum. Das doenças parasitárias, as parasitoses mistas foram as mais prevalentes com 37/59 casos, associadas principalmente ao nematódeo intestinal Ascaridia galli. As principais causas de morte nas aves desse estudo foram as parasitoses mistas, seguidas das salmoneloses aviárias (tifo aviário e pulorose). O sistema de criação e o manejo sanitário inadequado, tanto das aves quanto do ambiente, foram os principais fatores relacionados à ocorrência das doenças infecciosas diagnosticadas no LRD/UFPel.
\end{abstract}

Palavras-chave: Doenças de aves; Galinha caipira; Parasitose; Salmonelose.

\section{Abstract}

The objective of this study was to identify and to describe the main diseases that affect free-range chickens, sent to the Laboratório Regional de Diagnóstico of the Faculty of Veterinary Medicine of the Universidade Federal de Pelotas (LRD/UFPel), between the years 2000 and 2020. The necropsy protocols of domestic chickens referred to the LRD/UFPel in the last 20 years were reviewed. During this period, 565 samples were received corresponding to 
cadavers and organs of domestic chickens, 229 of which from free-range poultry farms. Out of 229 cases, 203 $(88,64 \%)$ had a conclusive diagnosis. The main diagnosed diseases were bacterial with 79/203 $(38,92 \%)$ cases, followed by parasitic 59/203 (29,06\%). Among bacterial diseases, salmonellosis was the most frequent with 26/79 cases, with 22/26 Gallinarum and 4/26 Pullorum biovars isolated. Parasitic diseases, mixed parasitosis were the most prevalent with 37/59 cases, mainly associated with the intestinal nematode Ascaridia galli. The main causes of death in free-range chickens in this study were mixed parasitosis, followed by avian salmonellosis (fowl typhoid and pullorum disease). The breeding system and inadequate sanitary management, both for chickens and for the environment, were the main factors related to the occurrence of infectious diseases diagnosed in the LRD/UFPel.

Keywords: Poultry diseases; Free-range chicken; Parasitosis; Salmonellosis.

\section{Resumen}

El objetivo de este estudio fue identificar y describir las principales enfermedades que afectaron a los pollos criados en sistemas alternativos, enviados al Laboratorio Regional de Diagnóstico de la Facultad de Medicina Veterinaria de la Universidad Federal de Pelotas (LRD/UFPel), entre 2000 y 2020. Se revisaron los protocolos de necropsia de pollos domésticos enviados al LRD/UFPel en los últimos 20 años. Durante este período se recibieron 565 muestras correspondientes a cadáveres y órganos de pollos domésticos, de los cuales 229 fueron de cría alternativa. De los 229 casos, $203(88,64 \%)$ tuvieron un diagnóstico concluyente. Las principales enfermedades diagnosticadas fueron bacterianas con 79/203 (38,92\%) casos, seguidas de las parasitarias 59/203 (29,06\%). Entre las enfermedades bacterianas, la salmonelosis fue la más frecuente con 26/79 casos, aislándose 22/26 biovars Gallinarum y 4/26 Pullorum. Entre las enfermedades parasitarias, los parásitos mixtos fueron los más prevalentes con 37/59 casos, principalmente asociados con el nematodo intestinal Ascaridia galli. Las principales causas de muerte en las aves de este estudio fueron la parasitosis mixta, seguida de la salmonelosis aviar (tifosis aviar y pullorosis). El sistema de cría y el inadecuado manejo sanitario, tanto de las aves como del medio ambiente, fueron los principales factores relacionados con la ocurrencia de enfermedades infecciosas diagnosticadas en la LRD/UFPel.

Palabras clave: Enfermedades de las aves; Gallina de campo; Parasitosis; Salmonelosis.

\section{Introdução}

A avicultura brasileira é classificada em industrial e alternativa, de acordo com o sistema de produção utilizado (Caires et al., 2010). A avicultura industrial consiste em um sistema intensivo de produção e a alternativa (colonial) em sistemas semi-intensivos (galinha caipira industrial) e extensivos (galinha de fundo de quintal) (Caires et al., 2010; Melendez et al., 2010), sendo a agricultura familiar a principal responsável pela implementação e manutenção da criação avícola colonial (Gomes Filho et al., 2014; Guelber Sales et al., 2015; Vieites, 2016).

As linhagens utilizadas nas criações alternativas são consideradas mais adaptadas ao modo de criação livre. Entretanto, o contato direto com outros animais domésticos e silvestres, torna essas aves e o ambiente no qual vivem potenciais reservatórios e fontes de infecção a diversos agentes infecciosos (Caires et al., 2010; Melendez et al., 2010; Gomes Filho et al., 2014; Guelber Sales et al., 2015).

A detecção de patógenos na avicultura alternativa contribui para a determinação de medidas sanitárias e manejo adequado das aves (Gomes Filho et al., 2014). Nos últimos anos a mudança no perfil dos consumidores, tem estimulado a utilização dos sistemas avícolas alternativos de produção (Caires et al., 2010; Vieites et al., 2016). Porém, estudos sobre a ocorrência das enfermidades que afetam aves criadas nesses sistemas são escassos, sendo abordando na maioria desses estudos apenas uma doença específica (Gomes Filho et al., 2014).

Com isso, o objetivo do presente estudo foi identificar e descrever as principais doenças diagnosticadas em galinhas coloniais encaminhadas ao Laboratório Regional de Diagnóstico da Faculdade de Veterinária da Universidade Federal de Pelotas, nos últimos 20 anos.

\section{Metodologia}

Foram pesquisados nos arquivos do Laboratório Regional de Diagnóstico da Faculdade de Veterinária da Universidade Federal de Pelotas (LRD/UFPel) os protocolos de necropsias realizadas em galinhas domésticas (Gallus gallus domesticus) de criações alternativas, encaminhadas entre Janeiro de 2000 e Janeiro de 2020. Foram analisados os dados 
epidemiológicos obtendo-se informações referentes à procedência dos animais, tipo de criação, alimentação, instalações e manejo sanitário. Foram avaliados, também, os sinais clínicos e evolução da doença, alterações macroscópicas e histopatológicas, bem como o diagnóstico que constava no protocolo original dos arquivos. Nos casos de doenças bacterianas, virais, fúngicas e parasitárias, amostras refrigeradas ou congeladas eram encaminhadas a laboratórios especializados parceiros ao LRD/UFPel, para a identificação do agente etiológico.

Os diagnósticos que constavam nos protocolos foram agrupados em diferentes categorias, de acordo com o agente etiológico em doenças bacterianas, virais, parasitárias e fúngicas, distúrbios metabólicos e nutricionais, lesões traumáticas e neoplasias. Os casos que não se enquadraram em nenhuma das etiologias mencionadas foram classificados como diagnósticos de etiologia indeterminada e inconclusivos.

\section{Resultados}

Foram recebidos no LRD/UFPel, de Janeiro de 2000 a janeiro de 2020, 565 amostras correspondentes a cadáveres e órgãos de galinhas domésticas oriundas dos municípios da área de abrangência do LRD/UFPel, sendo 336/565 amostras referentes a aves de criação industrial e 229/565 amostras provenientes de criações alternativas. Das 229 amostras 203(88,64\%) casos apresentavam diagnóstico conclusivo e em 26 (11,36\%) o diagnóstico foi inconclusivo. Dos 203 casos, 79 $(38,92 \%)$ corresponderam a doenças bacterianas, 59 (29,06\%) a doenças parasitárias, $29(14,29 \%)$ a doenças virais, $12(5,91 \%)$ doenças fúngicas (Tabela. 1), sete $(3,45 \%)$ a lesões traumáticas, seis $(2,96 \%)$ a distúrbios metabólicos e/ou nutricionais e três $(1,48 \%)$ a neoplasias. Oito casos $(3,94 \%)$ foram classificados como doenças de etiologia indeterminada (Tabela. 2$)$. 
Tabela 1 - Doenças bacterianas, doenças parasitárias, doenças virais e doenças fúngicas diagnosticadas em galinhas domésticas de criações alternativas no LRD/UFPel entre Janeiro de 2000 e Janeiro de 2020.

\begin{tabular}{|c|c|}
\hline Doenças bacterianas & Número de Casos n=79 (\%) \\
\hline Salmonelose ${ }^{a}$ & $26(32,91)$ \\
\hline Colibacilose & $17(21,52)$ \\
\hline Botulismo & $10(12,66)$ \\
\hline Tuberculose & $8(10,13)$ \\
\hline Aerossaculite e Pneumonia bacteriana ${ }^{b}$ & $7(8,86)$ \\
\hline Hepatite bacteriana $^{\mathrm{b}}$ & $4(5,06)$ \\
\hline Enterite bacteriana $^{\mathrm{b}}$ & $2(2,53)$ \\
\hline Pasteurelose & $2(2,53)$ \\
\hline Salpingite $^{\mathrm{b}}$ & $1(1,27)$ \\
\hline Septicemia $^{b}$ & $1(1,27)$ \\
\hline Traqueíte por Streptococcus spp. & $1(1,27)$ \\
\hline Doenças parasitárias & Número de Casos n=59 (\%) \\
\hline Parasitose Mista & $37(62,71)$ \\
\hline Coccidiose & $12(20,34)$ \\
\hline Histomoníase & $5(8,47)$ \\
\hline Singamose & $5(8,47)$ \\
\hline Doenças virais & Número de Casos n=29 (\%) \\
\hline Leucose aviária & $12(41,38)$ \\
\hline Doença de Marek & $8(27,59)$ \\
\hline Bouba aviária & $5(17,24)$ \\
\hline Gumboro & $2(6,90)$ \\
\hline Bronquite infecciosa & $1(3,45)$ \\
\hline Enterite não supurativa $^{c}$ & $1(3,45)$ \\
\hline Doenças fúngicas & Número de Casos n=12 (\%) \\
\hline Aspergilose & $11(91,67)$ \\
\hline Candidíase & $1(8,33)$ \\
\hline
\end{tabular}

a Salmonella Gallinarum e S. Pullorum.

b Diagnóstico morfológico, com lesões histológicas características de agente bacteriano, porém sem identificação do agente etiológico.

c Diagnóstico morfológico baseado nos achados histológicos característicos de agente viral, porém sem identificação do agente etiológico.

Fonte: Autores. 
Tabela 2 - Lesões traumáticas, distúrbios metabólicos e/ou nutricionais, neoplasias e doenças de etiologia indeterminada diagnosticadas em galinhas domésticas de criações alternativas no LRD/UFPel entre Janeiro de 2000 e Janeiro de 2020.

\begin{tabular}{lc}
\hline Doenças não infecciosas & \\
\hline Lesões traumáticas & Número de Casos n=7 (\%) \\
Politraumatismo & $3(42,86)$ \\
Miosite traumática & $2(28,57)$ \\
Granuloma por trauma a & $2(12,82)$ \\
Distúrbios metabólicos e nutricionais & Número de Casos n=6 (\%) \\
Enterite associada a distúrbio nutricional & $4(66,67)$ \\
Esteatose hepática & $2(33,33)$ \\
Neoplasias & Número de Casos n=3 (\%) \\
Teratoma & $1(33,33)$ \\
Carcinoma de células escamosas & $1(33,33)$ \\
Colangiocarcinoma & $1(33,33)$ \\
Doenças de etiologia indeterminada & Número de Casos n=8 (\%) \\
Enterite inespecífica & $3(37,50)$ \\
Degeneração e necrose hepática & $2(25,00)$ \\
Bursite necrosante & $1(12,50)$ \\
Poliartrite & $1(12,50)$ \\
Granuloma esplênico & $1(12,50)$ \\
\hline
\end{tabular}

${ }^{a}$ Lesão por corpo estranho em esôfago e lesão traumática em músculo esquelético. Fonte: Autores.

Nas doenças de causas bacterianas, a salmonelose representou o maior número de casos, com 26/79 diagnósticos, sendo 22/26 casos de tifo aviário e 4/26 de pulorose (Figura 1A, 1B). A colibacilose foi a segunda causa bacteriana de mortalidade mais prevalente dos protocolos revisados, com 17/79 casos (Figura 1C). As parasitoses mistas com 37/59 casos foram as mais relevantes entre as doenças parasitárias (Figura 1E), sendo considerados dois ou mais parasitas como causa da morte das aves necropsiadas. Na maioria dos casos nos quais os parasitas foram submetidos à identificação observou-se uma prevalência do nematódeo Ascaridia galli associado a outros nematódeos e cestódeos. Os agentes virais foram a terceira causa de morte de maior ocorrência, com 29 casos, sendo a leucose aviária a mais prevalente entre esses, com 12/29 casos (Figura 1D). Ainda, entre os diagnósticos de maior ocorrência de acordo com a etiologia, a aspergilose aviária foi a doença fúngica mais importante correspondendo 11/12 casos (Figura 1F). 
Figura 1 - 1A - Lesão hepática de tifo aviário em galinha doméstica. Fígado aumentado de tamanho, com áreas brancacentas multifocais (setas) na superfície capsular hepática. 1B - Lesão hepática de pulorose em galinha doméstica. Fígado discretamente aumentado de tamanho, com áreas brancacentas multifocais (seta) na superfície capsular hepática. 1C - Lesão em sacos aéreos por colibacilose em galinha doméstica. Sacos aéreos anteriores preenchidos por material amarelado de aspecto caseoso (asteriscos). 1D - Lesão hepática de leucose aviária em galinha doméstica. Nódulos brancacentos, multifocais, estendendo-se da cápsula ao parênquima hepático. 1E - Parasitose intestinal em galinha doméstica. Abertura de segmento de intestino delgado contendo infestação massiva de nematódeos morfologicamente compatíveis com Ascaridia galli. 1F - Lesão pulmonar de aspergilose aviária em ave jovem. Pulmões apresentando lesões nodulares multifocais a coalescentes, brancoamareladas e firmes (seta).

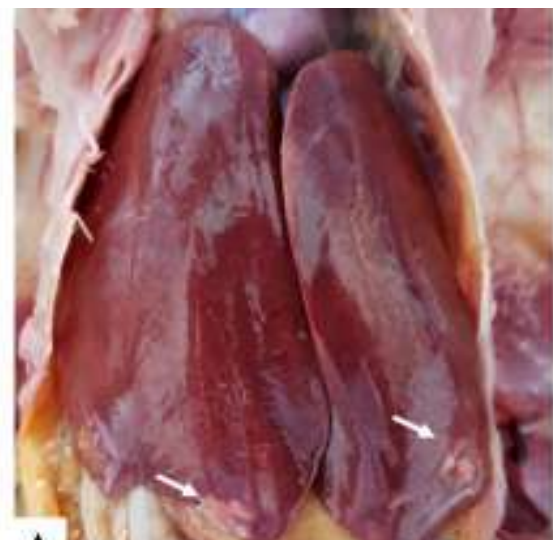

A
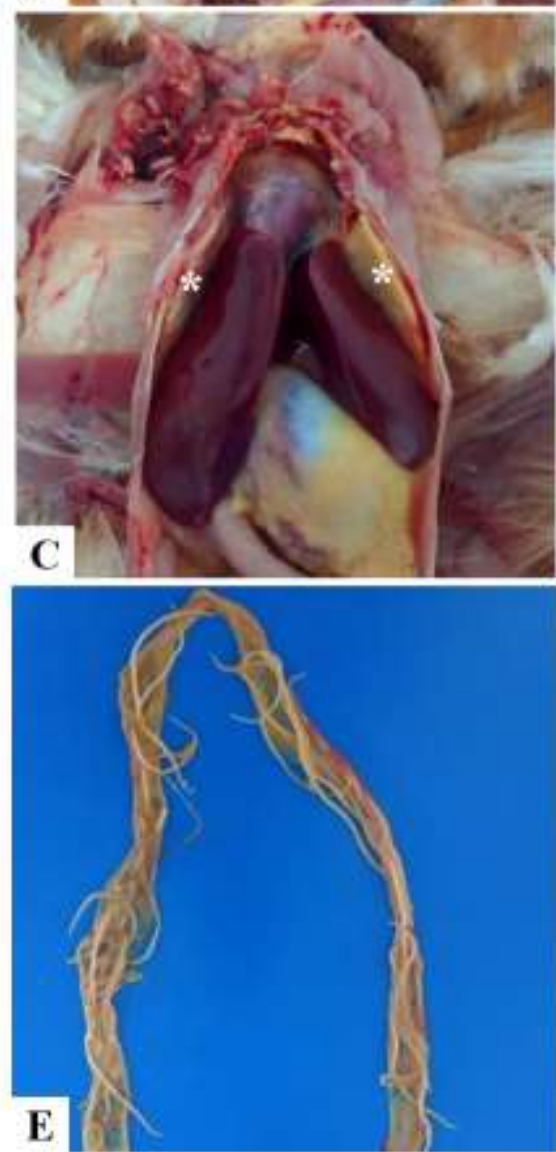

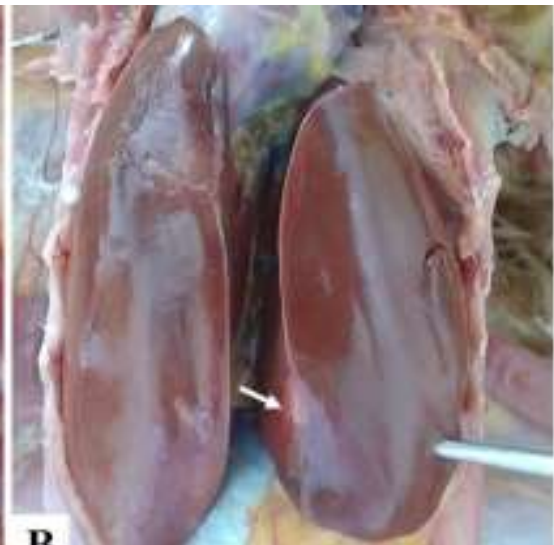

B
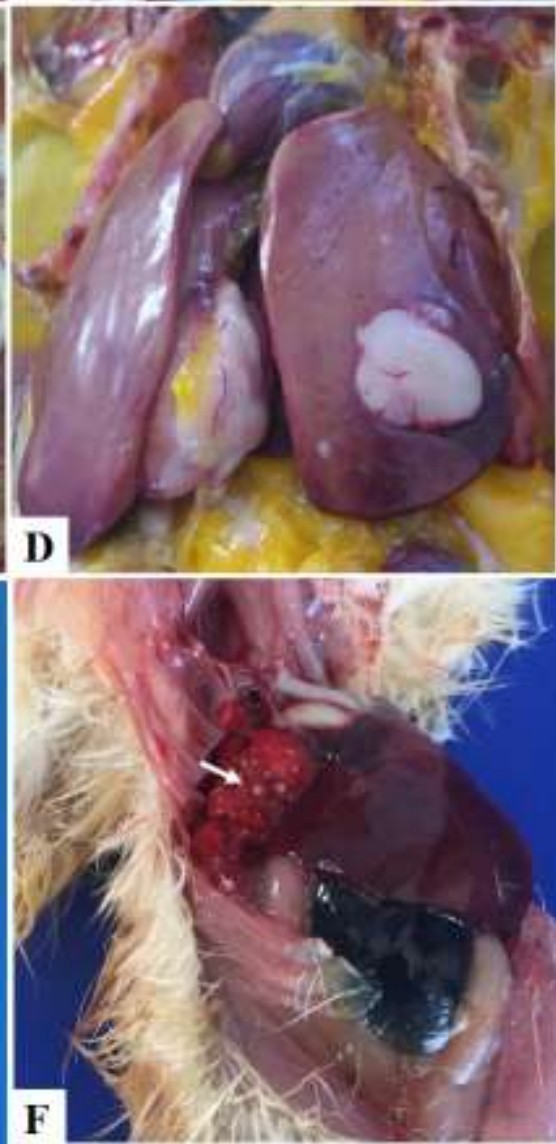

Fonte: Autores. 


\section{Discussão}

O presente estudo demonstrou que as doenças infecciosas foram as principais causas de morte em galinhas de criação colonial encaminhadas ao LRD/UFPel nos últimos 20 anos, correspondendo a 88,18\% (179/203) dos casos.

Dentre as doenças bacterianas, a salmonelose aviária foi o diagnóstico de maior ocorrência com 26/79 casos. Em 22/26 desses casos o diagnóstico foi correspondente a tifo aviário e em 4/26 a pulorose, confirmados mediante o isolamento de Salmonella Gallinarum e S. Pullorum, respectivamente. Dos sorotipos de Salmonella, o Gallinarum biovares Gallinarum e Pullorum são os de maior importância no setor avícola, adaptados as aves e responsáveis por altas taxas de morbidade e mortalidade (Barrow \& Freitas Neto, 2011; Barrow et al., 2012; De Carli et al., 2017; Wigley, 2017). Aves domésticas criadas em sistemas alternativos têm contato direto com outras aves domésticas de diferentes categorias e espécies e animais sinantrópicos (Buchala et al., 2006), favorecendo principalmente a infecção pela $S$. Gallinarum (Barrow \& Freitas Neto, 2011). Acredita-se que a maior prevalência do biovar Gallinarum observado nos casos diagnosticados no LRD/UFPel, está relacionada a ocorrência do contato interespécies nas criações estudadas. Outras práticas observadas nos casos diagnosticados de salmoneloses descritos nesse estudo, foram a troca de ovos embrionados entre criações e a compra de aves de linhagens comerciais sem procedência, predispondo a disseminação dos diferentes biovares de Salmonella.

A colibacilose aviária foi a segunda doença bacteriana de maior ocorrência em aves de criação colonial encaminhadas ao LRD/UFPel. Na avicultura intensiva, a colibacilose é considerada a principal causa infecciosa de condenação total de carcaça de frangos no sul do Brasil (Ferreira \& Knöbe, 2008). Dentre os principais fatores relacionados a sua ocorrência nas criações industriais, os fatores ambientais relacionados às altas concentrações de amônia, a deficiência na ventilação, grandes variações de temperatura, umidade da cama, alta densidade nos lotes e a desinfecção ineficiente das instalações predispõem as infecções respiratórias por Escherichia coli, que evoluem para a colisepticemia nas aves (Barnes et al., 2008; Ferreira \& Knöbe, 2008; Casagrande et al., 2017). Em contrapartida nas criações alternativas as aves são criadas livres e com baixa densidade populacional, apresentando uma menor predisposição a ocorrência de colibacilose (Casagrande et al., 2017), sendo considerado este o fator relacionado a menor ocorrência dessa patologia no presente estudo.

As parasitoses estão entre as mais frequentes causas de mortalidade que acometeram as galinhas domésticas encaminhadas ao LRD/UFPel. Segundo os protocolos de necropsia o diagnóstico definitivo nesses casos foi baseado nas infecções massivas e ausência de achados histopatológicos e laboratoriais relacionados a outras patologias. A criação de forma livre das aves, juntamente com o contato direto com o solo e a usual prática de criação avícola consorciada, associadas às condições ambientais e a ausência de uma rotina de vermifugação das aves e desinfecção ambiental, predispõe a infecção por diferentes parasitas (Baboolal et al., 2012; Quadros et al., 2015). Em todos os casos de parasitoses desse estudo, considerou-se a ausência ou realização esporádica de vermifugação o fator limitante para a ocorrência das mortes. Uma vez que a utilização incorreta desses protocolos, não interrompe o ciclo dos parasitas, mantendo aves e ambiente com alta carga parasitária (Baboolal et al., 2012; Radfar et al., 2012). Ainda, deve-se considerar que a ampla variação de espécie de helmintos e protozoários identificados nesse estudo, assim como em outros estudos está diretamente relacionada ao ambiente e manejo desses animais (Baboolal et al., 2012; Radfar et al., 2012; Quadros et al., 2015).

No presente estudo, a leucose aviária foi a patologia de causa viral mais frequente com 12/29 casos diagnosticados. Em um estudo realizado entre os anos de 2000 e 2016 na região sul do Rio Grande do Sul, as principais doenças virais diagnosticadas em aves domésticas foram Doença de Marek (DM) e Doença de Gumboro, no entanto, nesse trabalho foram incluídas aves de criações industriais e alternativas (Hirschmann et al., 2019). Deve-se considerar, que a transmissão dos vírus tanto de Marek quanto de Gumboro estão relacionados principalmente a problemas de biosseguridade nos incubatórios das granjas (Hirschmann et al., 2019), não sendo este um grande risco para as criações coloniais, uma vez que, somente uma pequena parcela dessas aves é adquirida de criatórios industriais. Outro fato relevante no presente estudo, que deve ser 
considerado, é que todas as galinhas afetadas tinham contato com aves silvestres, fator epidemiológico importante, pois, aves silvestres são consideradas disseminadoras do vírus da leucose aviária para as criações domésticas (Rocha et al., 2009).

A aspergilose aviária foi à afecção fúngica mais frequente observada nos casos analisados com 11/12 diagnósticos. Aspergilose é uma causa frequente de pneumonia e aerossaculite granulomatosa em aves, principalmente jovens, com maior importância econômica para o setor avicultura industrial (Arné et al., 2011; Dutta et al., 2017), sendo poucos os casos descritos em criações semi-intensivas ou extensivas (Zamboni et al, 2020). Os fatores predisponentes relacionados ao desenvolvimento e altas concentrações do fungo Aspergillus spp. no ambiente dos aviários (Beernaert et al., 2010; Arné et al., 2011; Chotirmall et al., 2013) são menos frequentes em criações avícolas alternativas, principalmente em sistemas extensivos.

As doenças não infecciosas e sem etiologia determinada representaram somente 11,82\% (24/203) dos diagnósticos conclusivos, sendo considerados casos individuais, ou acidentais como nos casos de traumatismos, sem relevância epidemiológica para as criações analisadas.

\section{Considerações Finais}

As principais causas de morte nas aves desse estudo foram as parasitoses mistas, seguidas das salmoneloses aviárias (tifo aviário e pulorose). O sistema de criação alternativo e o manejo sanitário inadequado, tanto das aves quanto do ambiente, foram os principais fatores relacionados à ocorrência das doenças infecciosas diagnosticadas no LRD/UFPel.

\section{Referências}

Arné, P., Thierry, S., Wang, D., Deville, M., Le Loc'h, G., Desoutter, A., Féménia, F., Nieguitsila, A., Huang, W., Chermetté, R., \& Guillot, J. (2011). Aspergillus fumigatus in Poultry. International Journal of Microbiology, ID746356: 1-14.

Baboolal, V., Suratsingh, V., Gyan, L., Brown, G., Offiah, N. V., Adesiyun, A. A., \& Basu, A. K. (2012). The prevalence of intestinal helminths in broiler chickens in Trinidad. Veterinarski Arhiv, 82(6): 591-597.

Barnes, H. J., Nolan, L. K., \& Vaillancourt, J. P. (, 2008). Colibacillosis. In: Saif, Y. M. Diseases of poultry. (12a ed.), Blackwell, $691-737$.

Barrow, P. A., Jones, M. A., Smith, A. L., \& Wigley, P. (2012). The long view: Salmonella - the last forty years. Avian Pathology, 41(5): 413-420.

Barrow, P. \& Freitas Neto, O. C. (2011). Pullorum disease and fowl typhoid-new thoughts on old diseases: a review. Avian Pathology, 40(1): 1-13.

Brasil, Ministério da Agricultura, Pecuária e Abastecimento. (2009). PNSA: Programa Nacional de Sanidade Avícola. Manual de Legislação: programas nacionais de saúde animal do Brasil/Ministério da Agricultura, Pecuária e Abastecimento. Secretaria de Defesa Agropecuária. Departamento de Saúde Animal. - Brasília: MAPA/SDA/DSA, 171-241.

Buchala, F. G., Ishizuka, M. M., Mathias, L. A., Berchieri Júnior, A., Castro, A. G. M., Cardoso, A. L. S. P., Tessari, E. N. C., \& Kanashiro, A. M. I. (2006). Ocorrência de reação sorológica contra Salmonella Pullorum em aves de "fundo de quintal" do estado de São Paulo, Brasil. Arquivos do Instituto Biológico, 73(1): $1-5$.

Caires, C. M., De Carvalho, A. P., \& Caires, R. M. (2010). Criação Alternativa de Frangos de Corte. Nutritime, 7(2): 1169-1174.

Casagrande, R. A., Machado, G., Guerra, P. R., Castro, L. A., Spanamberg, A., Silva, S. C., Cardoso, M. R. I., \& Driemeier, D. (2017). Caracterização anatomopatológica e bacteriológica em frangos de corte condenados totalmente por colibacilose sob Serviço de Inspeção Federal. Pesquisa Veterinária Brasileira, 37(9): 949-957.

Chotirmall, S.H., Al-Alawi, M., Mirkovic, B., Lavelle, G., Logan, P. M., Greene, C. M., \& Mcelvaney, N. G. (2013). Aspergillus-associated airway disease, inflammation, and the innate immune response. BioMed Research International, ID723129: 1-14.

De Carli, S., Gräf, T., Kipper, D., Lehmann, F. K. M., Zanetti, N., Siqueira, F. M., Cibulski, S., Fonseca, A. S. K., Ikuta, N., \& Lunge, V. R. (2017). Molecular and phylogenetic analyses of Salmonella Gallinarum trace the origin and diversification of recent outbreaks of fowl typhoid in poultry farms. Veterinary Microbiology, 212: 80-86.

Dutta, B., Konch, P., Konch, C., Gogoi, S. M., Farhad, H. M., \& Kakoty, S. P. (2017). Clinicopathological studies of Brooder pneumonia in Broiler Chicken. International Journal of Chemical Studies, 5(3): 510-512.

Ferreira, A. J. P., Knöbl, T. Colibacilose. In: Berchieri Jr, A., Silva, E. N., Di Fábio, J., Sesti, L., \& Zuanaze, M. A. Z. (2009). Eds. Doença das Aves. Campinas: FACTA, 457-482.

Gomes Filho, V. J. R., Teixeira, R. S. C., Lopes, E. S., Albuquerque, A. H., Lima, S. V. G., Horn, R. V., Rocha-E-Silva, R. C., \& Cardoso, W. M. (2014). Pesquisa de Salmonella spp. em galinhas criadas em fundo de quintal (Gallus gallus domesticus) e ovos comercializados nas feiras livres na cidade de Fortaleza, Ceará. Semina: Ciências Agrárias, 35(4): 1855-1864. 
Research, Society and Development, v. 10, n. 10, e467101018978, 2021

(CC BY 4.0) | ISSN 2525-3409 | DOI: http://dx.doi.org/10.33448/rsd-v10i10.18978

Guelber Sales, M. N., Barros, B. L. A., Máximo, H. L., Setúbal, R. L., \& Sales, E. F. (2015). Caracterização da criação de galinhas caipiras em sistema agroecológico. In: IX Congresso Brasileiro de Agroecologia, 2015. Cadernos de Agroecologia, 10(3).

Hirschmann, L. C., Fischer, G., Hübner, S. O., Lima, M., \& Vargas, G. D. A. (2019). Fatores de risco associados com a presença de infecções virais em aves domésticas na região Sul do Rio Grande do Sul, Brasil. Acta Scientiae Veterinariae, 47: 1642.

Melendez, S. N., Hanning, I., Han, J., Nayak, R., Clement, A. R., Wooming, A., Hererra, P., Jones, F. T., Foley, S. L., \& Ricke, S. C. (2010). Salmonella enterica isolates from pasture-raised poultry exhibit antimicrobial resistance and class I integrons. Journal of Applied Microbiology, 109(6): 1957-1966.

OIE - World Organization for Animal Health. (2020). Fowl Typhoid and Pullorum diseases. World Animal Health Information Database (WAHID). <https://www.oie.int/wahis_2/public/wahid.php/Diseaseinformation/statusdetail>

Quadros, R. M., Wiggers, S. B., Paes, M. P. V., \& Marques, S. M. T. (2015). Prevalência de endo e ectoparasitos de galinhas caipiras em pequenas propriedades da região serrana de Santa Catarina. PUBVET - Publicações em Medicina Veterinária e Zootecnia, 9(1): 1-5.

Radfar, M. H., Khedri, J., Adinehbeigi, K., Nabavi, R., \& Rahmani, K. (2012). Prevalence of parasites and associated risk factors in domestic pigeons (Columba livia domestica) and free-range backyard chickens of Sistan region, east of Iran. Journal of Parasitic Diseases, 36(2): 220-225.

Rocha, J. R., Antonio, N. S., Pereira, R. E. P., \& Lot, R. F. E. (2009). Leucose aviária: relato de caso. Revista Científica Eletrônica de Medicina Veterinária, 7(13): $1-5$.

Vieites, F., Souza, C. S., \& Salinas, J. A. P. (2016). Bien estar animal em los procesos de producción avícola -experiencias brasileras. Revista Colombiana de Zootecnia, 2(3): 17-22.

Vielitz, E. (2016). Evolution of avian pathology in Europe during the past 50 years. Lohmann Information, 50(1): 4-10.

Wigley, P. (2017). Salmonella enterica serovar Gallinarum: addressing fundamental questions in bacteriology sixty years on from the $9 \mathrm{R}$ vaccine. Avian Pathology, 46(2): 119-124.

Zamboni, R., Alberti, T. S., Scheid, H. V., Venancio, F. R., Brunner, C. B., Martins, O. A., Raffi, M. B., \& Sallis, E. S. V. (2020). Outbreak of avian aspergillosis in colonial-bred chicks (Isa Brown) in southern Rio Grande do Sul - case report. Arquivo Brasileiro de Medicina Veterinária e Zootecnia, 72(4): 1363-1368. 